\title{
“EU, CIENTISTA?!”: TRAJETÓRIAS NEGRAS E AÇÕES AFIRMATIVAS NA UFRGS ${ }^{1}$
}

\author{
Vera Rodrigues ${ }^{2}$ \\ Luanda Sito ${ }^{3}$
}

Resumo: Este artigo resulta da participação no edital "Negros e Negras nas Ciências", promovido pela Fundação Carlos Chagas, em 2016, com o projeto de pesquisa "Trajetórias Negras e Ações Afirmativas na Universidade Federal do Rio Grande do Sul", cujo objetivo era caracterizar demandas e experiências de estudantes cotistas e identificar suas boas práticas de permanência na universidade, com ênfase nas estratégias e desafios do ingresso, permanência e sucesso na vida universitária. Com esse foco, na linha "Experiências e boas práticas voltadas para atrair e qualificar jovens nas áreas de Ciências Exatas, Biológicas, da Saúde e Tecnológicas", levamos a cabo uma pesquisa qualitativa, que contemplou questionários e grupo focal com universitários negros, cotistas e não cotistas, de uma universidade pública do sul do Brasil (Universidade Federal do Rio Grande do Sul). Neste artigo, apresentaremos resultados que evidenciam obstáculos vividos pelos estudantes em seu ingresso, permanência e sucesso na vida universitária, como o enfrentamento ao racismo no meio acadêmico, e ao mesmo tempo estratégias que criam para lidar com esses desafios.

Palavras-chave: Ações Afirmativas; Ciência; Trajetória; UFRGS; Negro(a).

\section{" I, SCIENTIST ?!": BLACK TRAJECTORIES AND AFFIRMATIVE ACTIONS AT UFRG}

\begin{abstract}
This article results from the participation in the notice "Blacks in Science" , promoted by the Carlos Chagas Foundation in 2016, with the research project "Black Paths and Affirmative Actions at the Federal University of Rio Grande do Sul". characterize the demands and experiences of quota students and identify their good practices of permanence in the university, with emphasis on the strategies and challenges of admission, permanence and success in university life. With this focus, in the line "Experiences and good practices aimed at attracting and qualifying young people in the areas of Exact, Biological, Health and Technological Sciences", we carried out a qualitative research that included questionnaires and a focus group with black college students, not quota holders, from a public university in the south of Brazil (Federal University of Rio Grande do Sul). In this article, we will present results that demonstrate obstacles experienced by students in their entrance, permanence and success in university life, such as coping with racism in the academic world, and at the same time strategies they create to deal with these challenges.
\end{abstract}

\footnotetext{
1 A equipe de pesquisa foi composta pelas docentes Vera Rodrigues, da Universidade da Integração Internacional da Lusofonia Afro-brasileira - Unilab/Brasil, e Luanda Sito, doutora em Linguística Aplicada, docente na Universidade de Antioquia/Colômbia, e teve como assistentes de pesquisa Priscila Andréa da Cruz (graduanda em ciências sociais/UFRGS) e Alexandre Peres de Lima (mestrando em antropologia social/UFRGS).

${ }^{2}$ Doutora em Antropologia Social e docente na Universidade da Integração Internacional da Lusofonia Afrobrasileira - Unilab/Brasil.

${ }^{3}$ Doutora em Linguística Aplicada pela Universidade Estadual de Campinas-Unicamp (2016). Participa dos grupos de pesquisa Letramento do Professor (UNICAMP) e Educación y Diversidad Internacional (UdeAColômbia).
}

Revista da ABPN • v. 11, Ed. Especial - Caderno Temático: Raça Negra e Educação 30 anos depois: e agora, do que mais precisamos falar? • abril de 2019, p.207-230 
Key-words: Affirmative Actions; Science; Trajectory; UFRGS; Black.

\section{"MOI SCIENTIFIQUE?!": TRAJECTOIRES NOIRES ET ACTIONS AFFIRMATIVES À L'UFRGS}

Résumé: Cet article résulte de la participation à l'édit "Les noirs Negros en Science", promu par la Fondation Carlos Chagas en 2016, avec le projet de recherche "Chemins noirs et actions affirmatives de l'Université fédérale de Rio Grande do Sul". caractériser les demandes et les expériences des étudiants soumis aux quotas et identifier leurs bonnes pratiques de permanence à l'université, en mettant l'accent sur les stratégies et les défis d'admission, de permanence et de réussite dans la vie universitaire. Dans cette optique, dans la ligne "Expériences et bonnes pratiques visant à attirer et à qualifier les jeunes dans les domaines des sciences exactes, biologiques, de la santé et des technologies", nous avons mené une recherche qualitative comprenant des questionnaires et un groupe de discussion avec des étudiants noirs, non détenteurs de quotas, d'une université publique du sud du Brésil (Université fédérale de Rio Grande do Sul). Dans cet article, nous présenterons des résultats qui illustrent les obstacles rencontrés par les étudiants dans leur entrée, leur permanence et leur réussite dans la vie universitaire, tels que la gestion du racisme dans le monde universitaire, ainsi que les stratégies qu'ils créent pour faire face à ces défis.

Mots-Clés: Actions Affirmatives; La Science; Trajectoire; UFRGS; Noir.

\section{"YO, CIENTÍFICO ?!": TRAYECTORIAS NEGRAS Y ACCIONES AFIRMATIVAS EN LA UFRGS}

Resumen: Este artículo resulta de la participación en el edicto "Negros y Negras en las Ciencias", promovido por la Fundación Carlos Chagas, en el 2016, con el proyecto de investigación "Trayectorias Negras y Acciones Afirmativas en la Universidad Federal de Rio Grande do Sul", cuyo objetivo era caracterizar demandas y experiencias de estudiantes cotistas e identificar sus buenas prácticas de permanencia en la universidad, con énfasis en las estrategias y desafíos del ingreso, permanencia y éxito en la vida universitaria. Con este enfoque, en la línea "Experiencias y buenas prácticas dirigidas a atraer y calificar a jóvenes en las áreas de Ciencias Exactas, Biológicas, de la Salud y Tecnológicas", llevamos a cabo una investigación cualitativa, que contempló cuestionarios y grupo focal con universitarios negros, no cotistas, de una universidad pública del sur de Brasil (Universidad Federal de Rio Grande do Sul). En este artículo, presentaremos resultados que evidencian obstáculos vividos por los estudiantes en su ingreso, permanencia y éxito en la vida universitaria, como el enfrentamiento al racismo en el medio académico, y al mismo tiempo estrategias que crean para lidiar con esos desafíos.

Palabras-clave: Acciones Afirmativas; La Ciencia; Trayectoria; UFRGS; Negro(a).

\section{"NAS COTAS NINGUÉM TOCA": DEBATES E EMBATES NA UFRGS}

No segundo semestre de 2016, nossa chegada em campo foi marcada por uma série de mobilizações que transformaram o cotidiano da universidade. Por uma parte, no cenário nacional, a reação popular diante das ameaças das políticas do governo Temer, as quais afetariam a continuidade das políticas afirmativas; uma delas, a Proposta de Emenda Constitucional 241, ameaça a manutenção do investimento na educação superior com as 
mudanças do Ministério de Educação e Cultura. Por outra, no cenário local, houve uma série de manifestações ${ }^{4}$ que passaram a ser nomeadas como "Movimento Ocupa", em grandeparte uma reação a propostas de retroceder na política de cotas, assim como ao sucateamento do ensino superior. Ao analisar o contexto por meio de observações e da mídia local, podemos descrever um pouco do cenário. O Conselho Universitário faria, no mês de setembro de 2016, uma revisão na política de cotas, e propunha uma alteração nas notas de ingresso. Diante desse processo, movimentos sociais e estudantes se mobilizaram para reivindicar a manutenção do modelo atual do sistema de cotas, com o fim de que não se reduzisse o ingresso oferecido pelo Programa de Ações Afirmativas.

O movimento ganhou força, reorientando o posicionamento da Reitoria frente ao tema. Em notas seguintes, a Reitoria teve de expressar explicitamente que não reduziria o ingresso pelo programa. Para defender a política afirmativa, as ocupações organizadas, em um primeiro momento, se somaram e ampliaram em meio a outras demandas de defesa da educação pública por meio de atividades de formação políticas, debates, discussões e espaços de reflexões coletivas sobre a educação do país. Esse cenário nos levou a buscar como os estudantes cotistas lidavam em termos de percepções, expectativas e estratégias em relação a sua existência na universidade.

\section{CONTEXTO: AÇÕES AFIRMATIVAS EM UMA UNIVERSIDADE PÚBLICA GAÚCHA}

Nosso cenário de pesquisa iniciou alguns anos antes, em meio ao intenso debate sobre as ações afirmativas no ensino superior, no ano de 2007, quando culminou um processo de cerca de dois anos de demandas mais intensas com a aprovação de um Programa de Ações Afirmativas na primeira universidade pública no sul do Brasil. O Programa de Ações Afirmativas da Universidade Federal do Rio Grande do Sul (UFRGS) foi construído

\footnotetext{
${ }^{4}$ Estudantes e movimento negro ocupam reitoria da UFRGS contra mudanças na política de cotas Sul21", por Débora Fogliatto, 22/set/2016, 18h39min. Disponível em: <http://www.sul21.com.br/jornal/estudantes-emovimento-negro- ocupam-reitoria-da-ufrgs-contra- mudancas-na-politica-de-cotas/>. "Estudantes ocupam reitoria da Ufrgs contra restrição na política de cotas", Correio do Povo, por Luiz Phelipe M., 23/09/2016. Disponível em: <http://www.correiodopovo.com.br/Noticias/Ensino\%20/2016/09/598513/Estudantesocupam-reitoria-da- Ufrgs-contra-restricao-na-politica-de-cotas>. "Manifestantes contrários a mudanças no ingresso por cotas ocupam reitoria da UFRGS", "Conselho Universitário deve votar proposta nesta sexta-feira", Zero Hora; Educação; 22/09/2016, 18h35min.
} 
a partir de um diálogo que se iniciou no seio dos movimentos sociais, em particular do movimento negro, e ganhou maior espaço na academia a partir de um projeto de extensão. Entre as narrativas que reconstroem aquele momento, estão fragmentos como este:

Foi nesse contexto no qual se reorganizaram grupos orientados para a implementação de ações afirmativas na U. como o Grupo de Trabalho de Ações Afirmativas (doravante GTAA). Esse Grupo de Trabalho constituiu-se no intuito de compreender e difundir as razões da necessária implantação das ações afirmativas, buscando promover o diálogo entre a universidade e a sociedade mais ampla. Suas ações priorizaram a articulação junto a outros grupos que também lutavam pela implantação de Ações Afirmativas na U., bem como a realizaçãode encontros e seminários para dialogar sobre o tema. Além disso, o GTAA encarregou-se de realizar o levantamento das necessidades específicas dos grupos que mais sofriam com a desigualdade estrutural da sociedade no acesso ao ensino superior, de formular novas propostas para implementação de Ações Afirmativas, tanto no espaço universitário (seu foco principal), quanto em campos como a educação básica e a saúde, e de promover um círculo de palestras sobre Ações Afirmativas, especificamente cotas. (Sito; Ferreira; Rodrigues, 2008, p. 120, grifos nossos)

Sito, Ferreira e Rodrigues (2008) descrevem em detalhe o contexto de aprovação da política, situando o ponto de partida desse processo na construção de um grupo de trabalho sobre ações afirmativas, que articulou principalmente estudantes, técnicos da universidade e ativistas de movimentos negros, indígena e social. Além disso, mostram como o grupo de trabalho de ações afirmativas foi um agente importante no processo, por ser um ator social que se propunha a organizar outros coletivos em prol de consolidar uma política afirmativa. Esse Grupo se constituiu ao criar diversos espaços para promover o diálogo entre a universidade e a sociedade mais ampla e se constituiu em um coletivo articulador.

A partir desses debates, o coletivo construiu uma proposta inicial, que foi apresentada à Comissão Especial Ações Afirmativas da Universidade, constituída por membros dos Conselhos Superiores, no final de 2006. Durante o primeiro semestre de 2007, houve uma série de debates nos Conselhos Superiores para análise da proposta; e, concomitantemente, o coletivo do Grupo de Trabalho de Ações Afirmativas (GTAA) continuou realizando visitas aos diretores de cada unidade (que seriam os votantes da proposta no Conselho Superior) e desenvolvendo atividades políticas em torno do tema. A proposta construída a partir dessa discussão foi finalizada na reunião do Conselho Universitário da Universidade, do dia 29 de 
junho de 2007, mediante a aprovação da Decisão n. 134/2007, que aprovou o Programa de Ações Afirmativas na universidade.

\section{O PROGRAMA DE AÇÕES AFIRMATIVAS NA UFRGS}

O programa foi instituído ${ }^{5}$ de forma que observamos que, no seu primeiro artigo, já define quem será o público do Programa de Ações Afirmativas: candidatos de comunidades indígenas, alunos egressos de escolas públicas, oriundos de classes populares e alunos egressos de escolas públicas que se autodeclarem negros. Dessa forma, o Programa tentou aliar critérios socioeconômicos, com a vinculação à escola pública, e critério étnico-racial, com a orientação a indígenas e negros.

Nessa primera versão do programa, indicamos a presença de dois tipos de ações que constituem o Programa: a reserva de vagas e a criação de vagas adicionais. A primeira ação orientada para os estudantes egressos de escolas públicas e para alunos egressos de escolas públicas autodeclarados negros, e a segunda, para populações indígenas. Por um lado, para candidatos egressos do Sistema Público de Ensino Fundamental e Médio, a medida consiste na reserva de um percentual de $30 \%$ do total de vagas dos cursos, das quais a metade é para os candidatos autodeclarados negros $(15 \%)$. Por outro, para os candidatos indígenas, o Programa de Ações Afirmativas da UPG disponibiliza dez vagas, cuja forma de distribuição é definida em diálogo com lideranças de comunidades indígenas, principalmente Guaranis e Kaingang, os dois principais grupos étnicos do estado. Essas vagas são criadas anualmente para atender aos estudantes indígenas especificamente. Para essas vagas, realiza-se um processo seletivo diferenciado para os inscritos. Também há diferenças na identificação étnico-racial de ambos os grupos: para os estudantes negros, exige-se a autodeclaração registrada na inscrição para o vestibular e assinada no momento da matrícula nas Comissões de Graduação (COMGRAD) dos cursos - órgão institucional indicado na decisão para um acompanhamento mais próximo aos estudantes; para os estudantes indígenas, a identificação é atribuída por um certificado assinado por lideranças da comunidade indígena do estudante ou da Fundação Nacional do Índio (Funai).

\footnotetext{
${ }^{5}$ Decisão n. 134/2007.
} 
Parece importante retomar os objetivos do Programa para situar a discussão do tema de ações afirmativas. Para isso, destacamos que os três últimos incisos (III-V) estão diretamente relacionados com a desconstrução de imaginários racializados e com a observação das condições de permanência desses estudantes. Para atingir esses objetivos, foram estabelecidas, em seu início, duas comissões de Acompanhamento - a Comissão de Acompanhamento dos Alunos do Programa de Ações Afirmativas, responsável pelas ações enfocadas nos estudantes ingressos pela reserva de vagas, e a Comissão de Acesso e Permanência do Estudante Indígena, responsável pela permanência e acesso, com a realização de um processo seletivo especial para os estudantes indígenas. Depois de cinco anos, no ano de 2012, o acompanhamento dos estudantes passou a ser parte de umúnico órgão: a Coordenadoria de Ações Afirmativas (CAF). A criação desse órgão se deve ao fato de que as comissões se mostraram ser estruturas insuficientes para administrar o Programa. Outro fator foi o crescimento do público do programa: em cinco anos, a Universidade contava com 1.445 estudantes egressos de escola pública autodeclarados negros e com cerca de 50 estudantes indígenas.

Em relação às vagas ofertadas no vestibular e o número de vagas que foram ocupadas no período de 2008 a 2012, conforme os dados da Tabela 1, por exemplo, no ano de 2008, havia 667 vagas destinadas para estudantes de escolas públicas autodeclarados negros (Epn), mas ingressou um número menor, 295; com isso, as 372 vagas restantes foram realocadas para os estudantes de escolas públicas (Ep), que ocuparam 1.020 vagas no total.

Tabela 1. Número e porcentagem de vagas ocupadas 2008-2012 - UFRGS

\begin{tabular}{|c|c|c|c|c|c|c|c|c|c|c|c|c|}
\hline \multirow{2}{*}{$\begin{array}{l}\text { MODALI- } \\
\text { DADE DE } \\
\text { INGRESSO }\end{array}$} & \multicolumn{2}{|r|}{2008} & \multicolumn{2}{|r|}{2009} & \multicolumn{2}{|r|}{2010} & \multicolumn{2}{|r|}{2011} & \multicolumn{2}{|r|}{2012} & \multicolumn{2}{|c|}{$\begin{array}{c}\text { TOTAL } \\
\text { ocupação }\end{array}$} \\
\hline & Oferta & Ocupação & Oferta & Ocupação & Oferta & Ocupação & Oferta & Ocupação & Oferta & Ocupação & $\mathrm{N}$ & $\%$ \\
\hline Universal & 2.978 & 2.997 & 3.148 & 3.170 & 3.419 & 3.417 & 3.460 & 3.489 & 3.650 & 3.715 & 16.788 & 69,86 \\
\hline Ep* & 667 & 1.020 & 704 & 1.151 & 771 & 1.246 & 779 & 1.239 & 820 & 1.141 & 5.797 & 24,12 \\
\hline Epn** & 667 & 295 & 704 & 231 & 771 & 247 & 779 & 265 & 820 & 407 & 1.445 & 6,01 \\
\hline Indígena & 10 & 9 & 10 & 9 & 10 & 10 & 10 & 10 & 10 & 10 & 48 & 96 \\
\hline
\end{tabular}

Fonte: Relatório de avaliação do período 2008-2012. *Ep - Egresso de escola pública. **Epn -

Egresso de escola pública autodeclarado negro. 
No caso dos estudantes negros, o número de vagas ocupadas apresenta muita variabilidade, e houve um incremento no ano de 2012 (407 vagas ocupadas). Ativistas do movimento negro reclamam da falta de divulgação do programa, explicando que ainda é necessário construir a imagem da universidade como um direito da população negra. Para os ativistas, uma maior visibilidade do programa poderia provocar maior adesão da juventude negra para participar do exame vestibular. Além de acolher essa crítica, acrescentaríamos que essa construção também é necessária para os estudantes indígenas e de classe popular. Retomaremos esse aspecto da visibilidade da política ao explorar os dados do grupo focal.

No relatório de 2015, esses dados são atualizados. Pelo objeto deste artigo, destacamos os dados de ingresso nos cursos de Ciências Exatas, Biológicas, Tecnológicas e da Saúde, comparando dados de acesso e diplomação, para observar como se comportam os números nessas áreas de saber.

Tabela 2. Dados Ingresso Estudantil

\begin{tabular}{|c|c|c|c|c|c|c|}
\hline Curso & Universal & PPI* & Universal & PPI & Universal & PPI \\
\hline & Total & Total & Egressos & Egressos & $\begin{array}{c}\text { Taxa dipl. } \\
\%\end{array}$ & $\begin{array}{c}\text { Taxa dipl. } \\
\%\end{array}$ \\
\hline 1. Agronomia & 119 & 5 & 70 & 0 & 58,8 & 0,0 \\
\hline $\begin{array}{l}\text { 2. Arquitetura e } \\
\text { urbanismo }\end{array}$ & 120 & 1 & 67 & 0 & 55,8 & 0,0 \\
\hline 3. Biomedicina & 90 & 1 & 59 & 0 & 65,5 & 0,0 \\
\hline 4. Biotecnologia & 20 & 1 & 17 & 0 & 85 & 0,0 \\
\hline $\begin{array}{l}\text { 5. Ciência da } \\
\text { computação }\end{array}$ & 141 & 4 & 86 & 1 & 60,9 & 25,0 \\
\hline $\begin{array}{l}\text { 6. Ciências } \\
\text { biológicas }\end{array}$ & 191 & 8 & 84 & 3 & 43,9 & 37,5 \\
\hline 7. Design & 61 & 0 & 30 & 0 & 49,1 & - \\
\hline $\begin{array}{l}\text { 8. Educação } \\
\text { Física }\end{array}$ & 295 & 24 & 166 & 12 & 56,2 & 50,0 \\
\hline 9. Enfermagem & 211 & 40 & 188 & 18 & 89,0 & 45,0 \\
\hline $\begin{array}{r}\text { 10. Engenharia } \\
\text { ambiental }\end{array}$ & 40 & 0 & 27 & 0 & 67,5 & - \\
\hline $\begin{array}{l}\text { 11. Engenharia } \\
\text { cartográfica }\end{array}$ & 17 & 3 & 4 & 1 & 23,5 & 33,3 \\
\hline $\begin{array}{r}\text { 12. Engenharia } \\
\text { civil }\end{array}$ & 188 & 7 & 100 & 3 & 55,2 & 42,8 \\
\hline $\begin{array}{l}\text { 13. Engenharia de } \\
\text { alimentos }\end{array}$ & 40 & 2 & 15 & 0 & 37,5 & 0,0 \\
\hline
\end{tabular}




\begin{tabular}{|c|c|c|c|c|c|c|}
\hline $\begin{array}{l}\text { 14. Engenharia de } \\
\text { computação }\end{array}$ & 115 & 8 & 55 & 1 & 47,8 & 12,5 \\
\hline $\begin{array}{l}\text { 15. Engenharia de } \\
\text { controle e automação }\end{array}$ & 40 & 2 & 20 & 0 & 50,0 & 0,0 \\
\hline $\begin{array}{l}\text { 16. Engenharia de } \\
\text { materiais }\end{array}$ & 40 & 3 & 27 & 0 & 67,5 & 0,0 \\
\hline $\begin{array}{l}\text { 17. Engenharia de } \\
\text { minas }\end{array}$ & 34 & 0 & 20 & 0 & 58,8 & - \\
\hline $\begin{array}{l}\text { 18. Engenharia de } \\
\text { produção }\end{array}$ & 84 & 7 & 77 & 1 & 91,6 & 14,2 \\
\hline $\begin{array}{l}\text { 19. Engenharia } \\
\text { elétrica }\end{array}$ & 98 & 7 & 60 & 0 & 61,2 & 0,0 \\
\hline $\begin{array}{l}\text { 20. Engenharia } \\
\text { mecânica }\end{array}$ & 144 & 6 & 74 & 1 & 51,3 & 16,6 \\
\hline $\begin{array}{l}\text { 21. Engenharia } \\
\text { metalúrgica }\end{array}$ & 71 & 5 & 45 & 0 & 63,3 & 0,0 \\
\hline $\begin{array}{l}\text { 22. Engenharia } \\
\text { química }\end{array}$ & 102 & 1 & 68 & 0 & 66,6 & 0,0 \\
\hline 23. Farmácia & 306 & 32 & 66 & 0 & 21,5 & 0,0 \\
\hline 24. Física & 267 & 10 & 47 & 0 & 17,6 & 0,0 \\
\hline 25. Fisioterapia & 40 & 3 & 19 & 1 & 47,5 & 33,3 \\
\hline 26. Fonoaudiologia & 60 & 4 & 49 & 3 & 81,6 & 75,0 \\
\hline 27. Matemática & 263 & 10 & 74 & 0 & 28,1 & 0,0 \\
\hline 28. Medicina & 170 & 0 & 166 & 0 & 97,6 & - \\
\hline $\begin{array}{l}\text { 29. Medicina } \\
\text { veterinária }\end{array}$ & 96 & 2 & 75 & 0 & 78,1 & 0,0 \\
\hline 30. Nutrição & 105 & 18 & 57 & 5 & 54,2 & 27,7 \\
\hline 31. Odontologia & 203 & 9 & 151 & 4 & 74,3 & 44,4 \\
\hline 32. Psicologia & 124 & 12 & 60 & 2 & 48,3 & 16,6 \\
\hline 33. Química & 135 & 10 & 81 & 1 & 60,0 & 10,0 \\
\hline 34. Saúde coletiva & 123 & 3 & 36 & 2 & 29,2 & 66,6 \\
\hline TOTAL & 4.153 & 248 & 2.240 & 59 & - & - \\
\hline
\end{tabular}

Fonte: Relatório Bianual do programa de Ações Afirmativas do período 2013-2015. Permanência e desempenho discente. *PPI: Estudantes autodeclarados Pretos, Pardos e Indígenas.

Com base no relatório da CAF, decidimos dar uma ênfase na tabela anterior sobre o total de alunos diplomados e taxa de diplomação, apenas no acesso universal e por reserva com autodeclaração racial, por conta do escopo desta pesquisa. Entre os dados apresentados, destacamos três aspectos: 
- Há dois cursos em que a taxa de diplomação foi maior para os estudantes de ingresso por reserva com autodeclaração racial: Engenharia cartográfica $(33,3)$ e Saúde coletiva $(66,6)$.

- Cursos em que a diferença na taxa de diplomação entre acesso universal e reserva etnicorracial não sobrepassam os 10 pontos: Ciências biológicas (37,5\%), Educação física (50\%), Fonoaudiologia (75\%).

- Dos 34 cursos das áreas de Ciências Exatas, Biológicas, da Saúde e Tecnológicas, há 13 que ainda não apresentam diplomação.

Embora haja diferenças significativas entre as taxas de diplomação de estudantes cotistas e não cotistas, a equipe do relatório da UFRGS alerta que, ao observar o êxito acadêmico em relação à diplomação, "é necessário considerarmos as já lembradas tendências históricas por curso, uma vez que um dos fatores mais fortemente relacionado a taxas de diplomação, do ponto de vista de análises multivariadas possíveis, é o curso" (UFRGS, 2015,12). Essa observação se dá, especialmente, porque demonstram que houve uma variação no período de 2008 a 2012 e de 2013 a 2015.

É importante destacar que, em 2013, com a política de cotas nacional, o processo da reserva para ingresso teve de ser revisto. Essa revisão no processo de ingresso, impede ter uma análise do período atual, acerca da diplomação. Segundo os avaliadores do Programa, no período 2008-2012, verifica-se significância na diferença entre cotistas e não cotistas em quase todas as situações acadêmicas, com maior número de ingressantes por reserva de vagas ativos e maior número de ingressantes pelo sistema universal afastados, diplomados (egressos) e evadidos. Com relação ao atual ciclo do Programa de Ações Afirmativas, que se refere ao período posterior à Lei de Cotas, em 2013, os dados indicam diferenças significativas na evasão e no afastamento de alunos do Universal (superior à hipótese nula; ou seja, a hipótese de que seria não haver diferenças entre os grupos) e no afastamento e evasão dos alunos cotistas (inferior à hipótese nula). Nesse caso, a interpretação indica que essas diferenças ainda têm pouca significância devido, acima de tudo, ao pouco tempo transcorrido desde o ingresso desses alunos. (UFRGS, 2015, p. 17)

Para sintetizar esta seção de contextualização, é preciso destacar que o acesso aos dados quantitativos foi dificultado pela cultura acadêmica de manter uma postura de sigilo sobre os dados discentes. Contudo, aproveitamos ao máximo aquelas informações sistematizadas nos dois relatórios realizados pelos órgãos de acompanhamento da política. 


\section{ASPECTOS METODOLÓGICOS DO TRABALHO DE CAMPO: A PARTICIPAÇÃO NAS CIÊNCIAS}

Nossa opção metodológica foi por uma abordagem qualitativa, com ênfase na proposta de um trabalho construído em diálogo e, portanto, relacional com nossos interlocutores na busca de um desenho estratégico da efetivação da pesquisa, conforme nos apontam Minayo e Sanches (1993). A metodologia qualitativa à qual nos afiliamos (Mason, 1996) caracteriza-se por usar técnicas descritivas e interpretativas que traduzem e expressam determinada realidade empírica dentro de um recorte de espaço e tempo. A geração dos dados proveniente da entrevista via questionário virtual seguida do roteiro para o grupo focal se deu na ótica de análise de processos de discussão e interação social (Barbour, 2009). Nesta seção, apresentaremos o desenho metodológico da pesquisa realizada, assim como os recortes que realizamos para este artigo. A realização do grupo focal foi desenvolvida em duas etapas, conforme segue:

- Etapa 01: elaboração e envio de um questionário virtual com vistas a estabelecer um perfil entre dez estudantes negros(as) indicados via egressos dos cursos ZPPV-Zumbi dos Pamares Pré-Vestibular e Esperança Popular, bem como outros estudantes contatados entre membros de coletivos negros estudantis da UFRGS, cotistas ou não.

- Etapa 02: Dentre os dez estudantes que responderam ao questionário inicial, seis compareceram para o grupo focal realizado no dia 12 de novembro de 2016 com vistas a estabelecer suas respectivas trajetórias na interface com as ações afirmativas. Esse grupo foi composto por cinco cotistas e um não cotista. Os cursos abrangidos foram Engenharia Civil (02); Medicina Veterinária (01); Engenharia Metalúrgica (01); Odontologia (01) e Ciências Contábeis (01).

Para fins de nomeação dos participantes do grupo focal, bem como de preservação dos seus nomes reais, optamos por fazer referências a intelectuais e cientistas negros(as) cujo destaque nas áreas de estudo em foco ou em outras áreas oferecem um contraponto à sub-representação negra nas ciências em geral. Assim, formamos o seguinte quadro de nomes e respectivos cursos.

\section{Quadro 1. Grupo Focal}

Revista da ABPN • v. 11, Ed. Especial - Caderno Temático: Raça Negra e Educação 30 anos depois: e agora, do que mais precisamos falar? • abril de 2019, p.207-230 


\begin{tabular}{|l|c|c|c|c|}
\hline \multicolumn{1}{|c|}{ Estudantes } & \multicolumn{1}{|c|}{$\begin{array}{c}\text { Cotist } \\
\mathbf{a}\end{array}$} & $\begin{array}{c}\text { Curso de } \\
\text { graduação }\end{array}$ & $\begin{array}{c}\text { Grupo de } \\
\text { pesquisa }\end{array}$ & $\begin{array}{c}\text { Interesse } \\
\text { para a pós- } \\
\text { graduação }\end{array}$ \\
\hline $\begin{array}{l}\text { 1. Enedina Alves } \\
\text { Marques }\end{array}$ & $\mathrm{Sim}$ & $\begin{array}{c}\text { Ciências } \\
\text { Contábeis }\end{array}$ & Não & $\begin{array}{c}\text { Sim, mas não } \\
\text { sabe qual }\end{array}$ \\
\hline $\begin{array}{l}\text { 2.Virginia Leone } \\
\text { Bicudo }\end{array}$ & $\begin{array}{c}\mathrm{Si} \\
\mathrm{m}\end{array}$ & Odontologia & Não & $\begin{array}{c}\text { Saúde } \\
\text { Coletiva }\end{array}$ \\
\hline $\begin{array}{l}\text { 3. Carolina Maria de } \\
\text { Jesus }\end{array}$ & $\begin{array}{c}\mathrm{Si} \\
\mathrm{m}\end{array}$ & $\begin{array}{c}\text { Medicina } \\
\text { Veterinária }\end{array}$ & $\begin{array}{c}\text { Sim, } \\
\text { extensão e } \\
\text { monitoria }\end{array}$ & $\begin{array}{c}\text { Especialização } \\
\text { em felinos ou } \\
\text { residência }\end{array}$ \\
\hline 4.Teodoro Sampaio & $\mathrm{Nã}$ & $\begin{array}{c}\text { Engenharia } \\
\text { Metalúrgica }\end{array}$ & Não lembra & Talvez \\
\hline 5.André Rebouças & $\mathrm{Si}$ & Engenharia Civil & Não & Sim \\
\hline 6. Milton Santos & $\mathrm{Si}$ & Engenharia Civil & $\begin{array}{c}\text { Programa de } \\
\text { Educação } \\
\text { Tutorial - PET } \\
\text { Civil }\end{array}$ & Sim \\
\hline & $\mathrm{m}$ & & \multicolumn{2}{|c|}{} \\
\hline
\end{tabular}

Fonte: Elaboração da autora.

Em termos de identidade de gênero participaram estudantes cisgêneros (5) e transgêneros (1). A faixa etária do grupo ficou entre 19 e 48 anos de idade. A participação feminina foi de $63,6 \%$, praticamente o dobro da masculina: $36,4 \%$. Cabe destacar que as mulheres foram as primeiras a responder ao questionário virtual.

\section{Gráfico 1. Gênero}

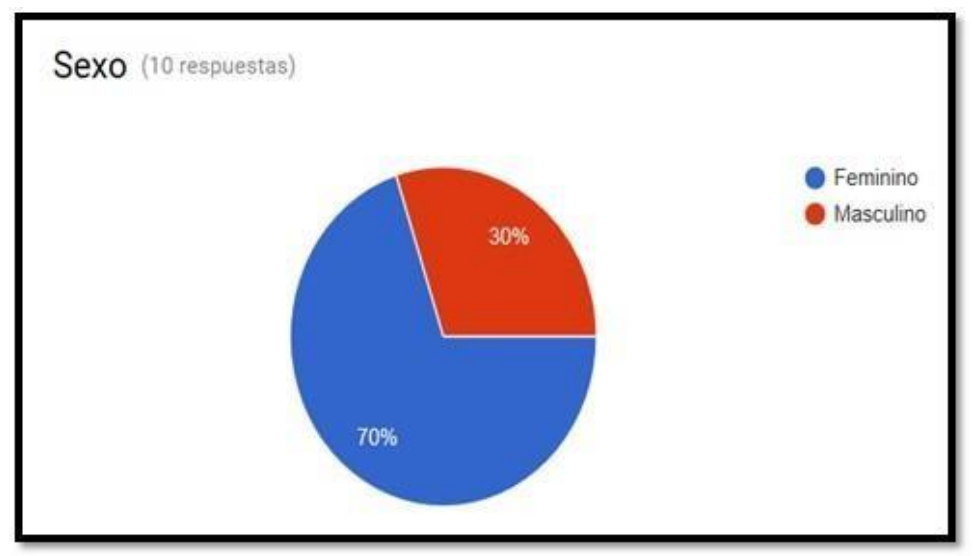

Fonte: elaboração da autora.

\footnotetext{
${ }^{6}$ Para maiores informações sobre os intelectuais nomeados consultar: Schumaher e Vital Brazil (2007) e Machado (2013).
} 
Pelo curto tempo da pesquisa, não se pôde chegar a uma análise dessa informação, mas nos parece importante registrá-la. Outra informação que mapeamos foi o estado civil dos participantes. Em sua maioria, eram solteiros e não tinham filhos. Nos dois casos em que havia filhos, os participantes tinham até dois filhos. No gráfico a seguir, apresentamos dados sobre o estado civil dos participantes.

\section{Gráfico 2. Estado civil dos participantes}

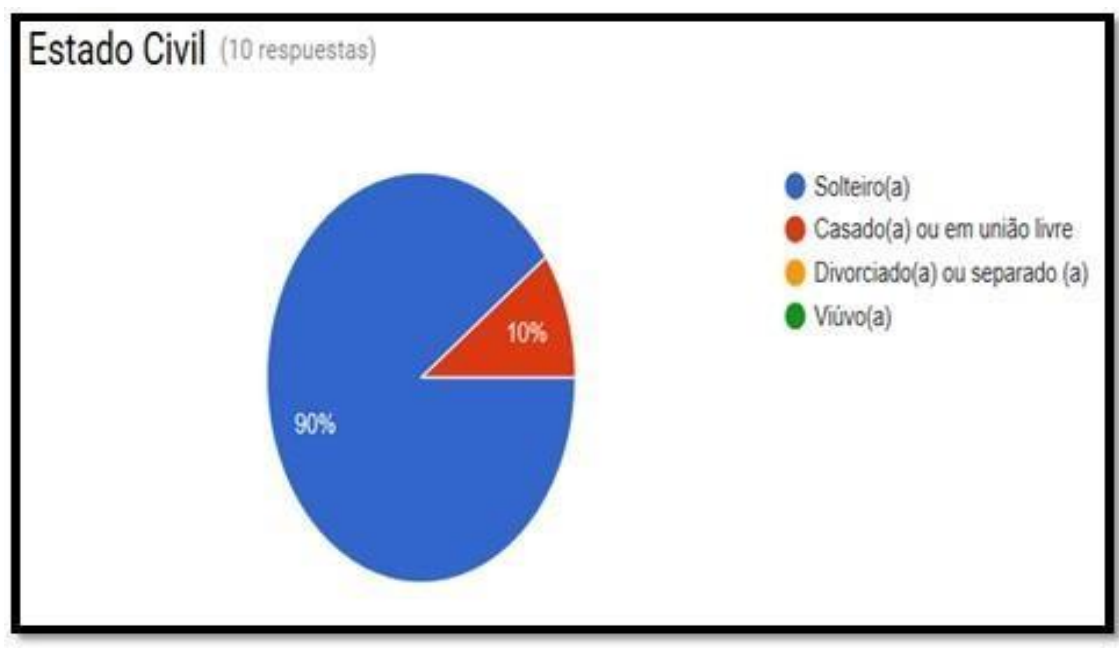

Fonte: elaboração da autora.

Também destacamos sobre o perfil do grupo focal a identidade racial autodeclarada por cada estudante. A pergunta do questionário se baseou nas categorias do IBGE-Instituto Brasileiro de Geografia e Estatística.

\section{Gráfico 3. Raça/Cor}

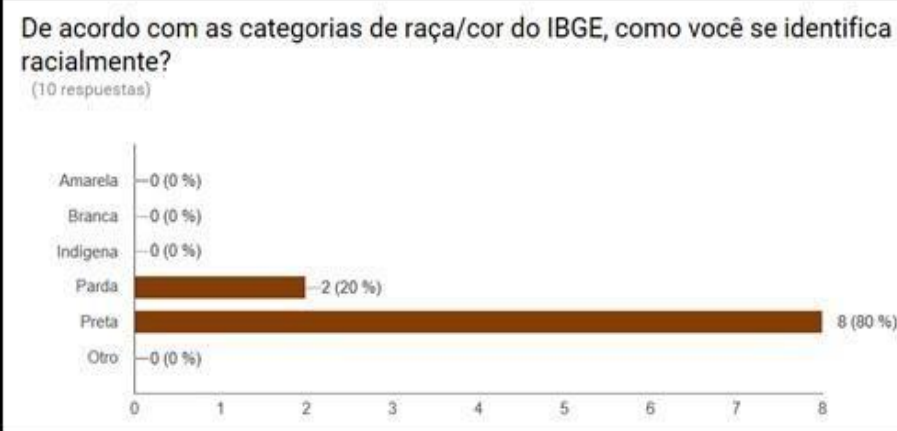

Fonte: elaboração da autora. 
Todos os participantes se identificaram como negros: dois pardos e oito pretos, conforme gráfico acima. Em relação a sua moradia, 2/3 dos estudantes participantes são da capital do estado, enquanto 1/3 vinha do interior ou de outro estado (Porto Alegre (6), Rio Grande (1), Carazinho (1) e Viamão (1) Bahia (1)). No caso daqueles que vivem em Porto Alegre, evidenciou-se a moradia em bairros periféricos da capital e região metropolitana, tais como Gravataí, Mario Quintana, Santa Tereza, Cefer, Lomba do Pinheiro e Jardim Fiuza. Outro dado foi que a maioria (9) dos estudantes reside com familiares.

Desse quadro-síntese, apresentamos um panorama sobre os estudantes participantes do grupo focal. Entre as primeiras observações, nos chamou atenção a pouca participação na pesquisa e no vislumbre da pós-graduação como possibilidade futura. Isso nos fez pensar nos entraves existentes entre esses âmbitos tão relevantes para pensar sobre a participação nas ciências. Isso porque, ao estarem à margem dos grupos de pesquisa e extensão, deixam de vivenciar espaços privilegiados de formação e acesso à pósgraduação, bem como aumento das possibilidades de êxito profissional.

A partir da análise dos discursos enunciados, traçamos algumas linhas interpretativas diante das trajetórias expostas nas narrativas. Nesse sentido, destacamos os grandes eixos temáticos que foram construídos durante essa constituição das trajetórias: família, ser negro(a), permanência na universidade, participação e perspectivas científicas.

\section{“O QUE ME FAZ RESISTIR DENTRO DA UNIVERSIDADE"}

Quando perguntados sobre a origem da motivação para ingressar na universidade pública, a maioria respondeu que a família era o ponto de partida da decisão de ingressar no ensino superior. Ainda que a geração anterior a eles(as) não tivesse tido acesso à educação formal em nível mais amplo, esse fator familiar esteve presente, como podemos ver nos excertos de entrevistas dos estudantes André, Enedina, Carolina e Miltom.

Miltom Santos-Engenharia Civil: O maior incentivo, assim, foi do meu pai, né, ele não completou o ensino médio, ele parou na quinta série, se eu não me engano, ai ele sempre falava pra mim, "Ah, tu tem que estudar, tem que estudar porque tu não pode seguir o mesmo caminho que eu, tu tem que seguir um melhor e o melhor jeito vai ser trabalhar, ou fazer o técnico ou fazer faculdade. Ai depois que eu ingressei meu pai também ficou falando, "Ah, tem que estudar porque quando se formar não quero ver tu saindo pra trabalhar, quero ver tu indo pra faculdade”. Aí 
foi mais isso, sempre meu pai e minha mãe me incentivando.

Enedina Alves Marques-Ciências Contábeis: Acho que comigo foi principalmente a minha irmã, foi a primeira pessoa da minha família a acessar uma universidade, $e$ ela acessou uma, ela fazia na UERGS[Universidade Estadual do Rio Grande do Sul] ali em Novo Hamburgo, e ai foi ela quem disse assim: "Ah, Enedina Alves Marques, tem que fazer, tem que tentar faculdade, tenta UFRGS, tenta UFRGS",

Carolina Maria de Jesus-Medicina Veterinária: É, acho que a família também, né, a minha mãe não tem ensino superior, nem minha avó também não tem, só tem o primário, e meu pai também, na época em que eu fui tentar vestibular eles sempre falavam, "ah, tem que fazer uma faculdade, tem que fazer uma faculdade"

O pai, a irmã ou a família de modo geral é enunciada em suas narrativas como sujeitos que os motivam e facilitam o acesso à universidade.

Somados à família emergem os cursos pré-vestibulares populares como espaços de motivação.

André Rebouças-Engenharia Civil: Tava procurando me encontrar na vida, e depois fui trabalhar no mercado, isso eu já tinha ido pro Zumbi um ano, né, no ano que foi quando tu me deu uma aula lá no Zumbi, naquela época. E aí eu fui trabalhar no mercado, e aí que eu comecei a cair em si, né, que tem que fazer faculdade, mas não tinha ideia sobre a UFRGS, né. Então a questão da universidade pública eu acho que ela foi mais presente, assim, que eu encontrei, foi lá no cursinho, porque daí tinha vocês, ne, tu, tinha outra professora, Júlia, professora de português que falava bastante, e o foco, também, do Zumbi, né, enfim, era isso(...)Dai a partir dai que eu tive um interesse, assim, despertou mais o interesse, né. Ai fiz o outro ano, dai acabei passando, né, que ai eu fiz. Física, eu sou formado em Física, era professor, também, fui professor um tempo, aí abandonei e retomei pra Engenharia civil e mais foi nessa época do Zumbi que eu tinha mais um caráter de ativismo, acho né. Naquela época estudei lá, assim... Então li também essas discussões das ações afirmativas, cotas e ainda eram discussões, né, não existiam ainda e foi lá, assim, que a grande transformação foi dentro do cursinho assim pra focar na UFRGS que eu até uma época até tava falando em casa, que eu lembro bem assim, sobre ah... pagar a faculdade, porque é basicamente isso aí. Trabalha, paga a faculdade é uma coisa meio que...

O estudante soma a motivação recebida do seu pai à sua participação no curso Zumbi dos Palmares Pré-Vestibular. Segundo ele, esse espaço formativo lhe trouxe uma visão de ativismo que, somada ao incentivo familiar, permitiu-lhe pensar na UFRGS como uma possibilidade real.

Revista da ABPN • v. 11, Ed. Especial - Caderno Temático: Raça Negra e Educação 30 anos depois: e agora, do que mais precisamos falar? • abril de 2019, p.207-230 
Debater as narrativas sobre sua motivação para ingressar na universidade abriu espaço para enunciar as tensões cotidianas de sua vida universitária. À medida que o diálogo fluía no grupo focal, os estudantes começavam a abordar o pertencimento racial agregado ou não à condição de cotista como elemento-chave para (re)pensar as barreiras enfrentadas na permanência na universidade.

\section{“O QUE ME FAZ QUERER DESISTIR DA UNIVERSIDADE"}

As narrativas sobre a cotidianidade, contada pelos estudantes negros(as), está marcada por eventos de invisibilidade e discriminação:

[...] eles ignoram” e “os professores são super racistas, por tu não ser o padrão de lá eles já te julgam e tipo se tu pergunta uma coisa eles ignoram o que tu tá perguntando porque tu não é o padrão da Odontologia.

Também se destacam os estereótipos e associação a imagens negativas pronunciados por docentes e colegas aos estudantes, conforme os extratos a seguir:

Virginia Leone Bicudo- Odontologia: Primeiro que na hipótese, tipo o acesso que tu sustentou é universal, é cotismo e tipo, se tu é negro eles vão te olhar como cotista, né. Se tu é negro dentro da universidade! Dentro do meu curso é bem difícil porque... antes de nós, eu acho que, deve ter um total tipo de umas cinco pessoas antes da minha turma e na minha turma foram mais quatro. Deve ter uns nove ou dez. Deve ter mais algum, sabe, tipo umas dez pessoas ao total dentro da faculdade e são mil alunos. Sabe... é bem difícil, dentro da Odonto eu me sinto uma pessoa que não combina onde eu to, inclusive em relação agora do que tá acontecendo dentro da UFGRS com ocupações, com o lance da PEC... porque a gente tentou fazer uma assembleia lá e foi a pior decepção. Os professores são super racistas, por tu não ser o padrão de lá eles já te julgam e tipo se tu pergunta uma coisa eles ignoram o que tu tá perguntando porque tu não é o padrão da Odontologia. Porque tu não é loira dos olhos azuis como é a maioria”

Teodoro Sampaio- Engenharia Mecânica: Se tu é negro, pra eles tu é cotista... Ah, sempre foi complicado, a engenharia em si é complicada, é um curso muito elitista, um curso muito preconceituoso, a gente não tem nenhum tipo de referência como professor negro, em si, os que a gente tem eles ignoram, como a Enedina Alves Marques comentou, se a gente levanta a mão, faz uma pergunta, o negro levanta a mão pra fazer uma pergunta, o branco faz a mesma pergunta, ele responde o branco, não responde ao negro... Em relação à cotistas, eu sempre fiquei muito lá no CT que é lá no campus do bairro, que a maioria dos laboratórios de engenharia

Revista da ABPN • v. 11, Ed. Especial - Caderno Temático: Raça Negra e Educação 30 anos depois: e agora, do que mais precisamos falar? • abril de 2019, p.207-230 
ficam lá, então eu sempre fiquei muito lá, assim, desde que eu tava antes de passar no vestibular, então eu conheço quase todos os laboratórios, quase todos os professores, e eles sempre falaram muito em relação à cotista, que muitos são contra e eles acham que sim, baixa o nível do curso, porque eles acham que eles entram no curso com um conhecimento muito baixo, então eles acham que baixa muito o nível do curso, isso aí... que não deveria ter cotista, eles são bem claros em relação à isso, assim. Inclusive um professor que eu tinha, que é do laboratório que eu tinha bolsa, na época, e ele sabia que eu não tinha cotas, ele achavaque era muito bom que eu não tinha cotas porque... porque baixava o nível do curso e era melhor pra mim não ter cotas, assim, entrar... Enfim, ele tinha essa postura, uma coisa assim, bem.

Carolina Maria de Jesus-Medicina Veterinária: É! Ou sei lá, às vezes a gente também tem aulas gerais sobre economia, planejamento, gestão por aula, essas coisas, sei lá às vezes o professor cita uns exemplos sabe, tipo... De outros países e cita sei lá, cita, por exemplo, sei lá a questão por aula “Aah a Africa só tem coitado”, porque a Holanda vai lá investir na África. "Investir na África” porque lá só tem coitadinho. E daí tu fica como na aula?

André Rebouças - Engenharia Civil: Eu vejo isso ai como uma realidade de vários cursos da UFRGS, né, assim, a questão do individualismo da pessoa, você é meio que escanteado, assim, na faculdade de Engenharia, na Física quando eu estudei, eu era o único negro, era o um por cento, assim. Mas é... isso daí é uma realidade do cotidiano da UFRGS, né, porque na verdade nós somos a exceção à regra dentro da UFRGS, né, não é a regra da UFRGS, a gente tá num mundo que é um mundo novo.

Miltom Santos-Engenharia Civil: Eu ando pelos corredores ali, eu vejo aqueles quadros de diplomas, de formandos, e eu não vejo nenhum negro, nenhum negro, só vi uma pessoa negra, só... Uma ou duas pessoas negras. Na minha turma de produção, que tinham oitenta alunos, eu só via três pessoas negras. Tinha bastante cotistas, assim, de outras classes, mas... Negros, eu só vi três pessoas. E quando eu ando, assim, por lá, eu me sinto meio que excluído, porque não tem nenhuma semelhança, não tem um grupo, assim, são todas pessoas brancas, falando das mesmas coisas, o mesmo cotidiano, os mesmos pensamentos..é, eu tenho meio que um receio, também.

Como se pode ver nos relatos, há um cotidiano permeado de violências simbólicas, sejam os exemplos de associação das referências de matriz africanas a pobreza ou a aspectos negativos, sejam os estereótipos enunciados nos discursos de sala de aula. Assim, os relatos expostos dão conta de uma experiência de estranhamento por parte da comunidade do entorno que é gerado pela identidade negro(a) dos estudantes, especialmente em cursos com baixa representatividade da população negra. O racismo aparece, em suas narrativas, traduzido na junção entre "ser negro" e "ser cotista" como fatores estigmatizantes.

Revista da ABPN • v. 11, Ed. Especial - Caderno Temático: Raça Negra e Educação 30 anos depois: e agora, do que mais precisamos falar? • abril de 2019, p.207-230 


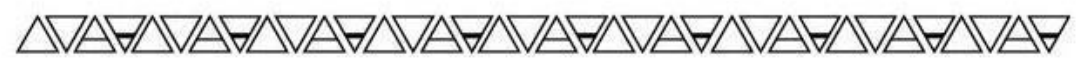

Outro dado que apareceu nas falas foi o papel dos docentes no processo de estigmatização racial, seja por silenciarem ou por reproduzirem isso no processo de ensinoaprendizagem ao desqualificarem o conhecimento relacionado ao sujeito negro ou ao continente africano, por exemplo. Os estudantes descrevem eventos nos quais os professores não respondem a suas perguntas e o invisibilizam na sala de aula. Isso pode ser pensado na ótica do quanto inibe a participação deles(as) na produção de conhecimento da sua respectiva área de formação.

\section{"LUTANDO PARA PERMANECER NA UNIVERSIDADE"}

Diante do tema da permanência na universidade, o grupo enunciou aquilo que considera os principais entraves à efetivação da vida acadêmica. Nesse enunciado, obviamente está presente o racismo associado ao tema anterior do "Ser negro(a)" em cursos em que a sub-representação é a norma. Em uma perspectiva interseccional, surgem elementos associados a gênero e condições socioeconômicas como desafios que demandam processos de resistência para permanecer na universidade.

Esse é o caso de Teodoro Sampaio (Engenharia metalúrgica), autodeclarado negro e homem-trans, nascido em uma cidade do interior do Rio Grande do Sul, ele não via possibilidades de crescimento profissional nessas condições:

Ah, sei lá, eu vim do interior, no interior não tinha aquela... aquela cultura de fazer faculdade, depois do ensino médio tu sai, tu vai trabalhar, vai ser lojista, sei lá, trabalhar numa loja, num super mercado, e eu já tinha uma certa ambição, que eu achava que lá não era meu lugar. Não sei se o pessoal percebeu, vou falar aqui, eu sou homem trans, então, tipo, a cidade pequena é meio complicada pra isso, até mesmo pra trabalho, eu era da área de informática, não tinha nem pra trabalhar de graça, assim, então eu pensei "tenho que sair daqui", dai eu sai de lá, mas trabalhar, na real.

Sua experiência mostra um número maior de obstáculos interpostos em sua trajetória universitária: teve de abandonar sua cidade natal, viver distante de sua família, com ingressos econômicos restritos. Esses aspectos se associam a eventos de discriminação “eu sou homem trans, então, tipo, a cidade pequena é meio complicada pra isso" que dificultam ainda mais sua permanência na universidade.

O tema de ser negro(a) nesses cursos trouxe um outro ponto de abordagem: como

Revista da ABPN • v. 11, Ed. Especial - Caderno Temático: Raça Negra e Educação 30 anos depois: e agora, do que mais precisamos falar? • abril de 2019, p.207-230 
lidar com o racismo e permanecer na universidade? Quais são os espaços e/ou mecanismos de resistência e/ou fortalecimento individual e/ou coletivo? Como forma de entender melhor como lidavam com esses conflitos que enunciavam, passamos a questionar sobre as estratégias que criavam para manter-se na universidade. Suas respostas orientaram-se nos seguintes eixos:

1) Grupos informais de amigos negros(as) colegas ou não de curso;

2) Grupos e/ou atividades constituídos como "coletivos negros" criados na universidade para agregar sociabilidade participação política e debate sobre ações afirmativas. Foram citados nas falas: "Negra Ação", "Sambaral”, "Balanta" e "Afronta";

3) A política estudantil com os auxílios voltados para alimentação, moradia e transporte.

Esses três eixos podem ser observados nos trechos a seguir:

Enedina Alves Marques- Ciências Contábeis: Eu acho que, tipo... O que me fez resistir dentro universidade, eu sempre falo quefoi um pouco da condição do coletivo, assim, que a gente construía, tipo, o NEGRAÇÃO assim, acho que... foi a base, assim, pra fazer, porque quando eu entrei, eu entrei em 2010, daí tipo, acho que foi em 2012, no processo de reavaliação, né, foi ainda quando eu conheci a Luanda, né, e eu lembro que naquela época, assim, era uma reunião, assim, de, do movimento negro, assim, né, e eu fui meio que de gaiata, assim, ai eu lembro até hoje que a Kelly falou assim, "Ah, quem é que sabe como foi a luta das ações afirmativas?"

Miltom Santos-Engenharia Civil: Um dos motivos que não me deixou desistir, claro, foi a questão de ter auxílio, de ter uma moradia, ter a refeição todo dia, ter um vale transporte, então isso é uma das coisas cruciais que não me deixaram desistir de início, então, foi o financeiro da universidade. Claro que tá precário, pode ser muito melhor, mas foi o que... e a segunda coisa é a de ser o primeiro graduado da minha família, primeira geração que tem graduação, não me lembro, assim, de nenhum primo meu, irmão, pai que... avô, tio, sei lá, que se graduou, então eu tenho um sonho de ser o primeiro da minha família a ser graduado e depois o meu irmão, também que faz medicina. Isso é um dos motivos que mais me deixa na luta.

Conforme apontávamos, os coletivos étnicos e o apoio à assistência estudantil, como Coletivo Negração e as bolsas, são alguns dos elementos que favorecem a permanência desses estudantes. Havendo fatores favoráveis à permanência, abrem-se as expectativas de concretização de uma carreira profissional.

Revista da ABPN • v. 11, Ed. Especial - Caderno Temático: Raça Negra e Educação 30 anos depois: e agora, do que mais precisamos falar? • abril de 2019, p.207-230 
A participação na pesquisa não é uma realidade na maioria dos cursos em foco, seja porque isso não faz parte da dinâmica do curso ou porque falta apoio docente para orientar projetos de interesse dos estudantes, que dialoguem com o campo das relações raciais. Uma estratégia muito importante é a seleção de professores(as) que os apoiem no curso. Nesse aspecto, observamos que há docentes que são referência para os estudantes, aspecto que se mostrou relevante. Entre os poucos docentes citados, estão professores negros ou alguns que são simpatizantes das ações afirmativas.

Enedina Alves Marques- Ciências Contábeis: Na contábeis não tem espaço pra pesquisa pra nada, assim, tipo, se tem é pra muito poucos...Na contábeis não tem assim. A única professora que agora no curso, que tive mais esse estritamente foi a professora Ana Tércia assim, que eu conheci ela, na verdade, quando eu entrei na contábeis e ai não deu um semestre e eu fiquei sabendo que tinha ela como professora no curso, né e ai falaram: "Ah, ela é a única professora negra da faculdade e tal" e daí eu passei todo o curso assim na expectativa de ter aula com ela e eu: "em algum momento eu vou ter aula com ela, né" e ai quando eu tava terminando no IPA, tipo eu fiz o TCC sobre professoras negras e sobre inserção e carreira docente daí eu entrevistei ela, né, e foi o primeiro contato que eu tive com ela, e aí depois quando eu tava quase me formando, na escolha da orientadora, assim, tipo que eu fiz... na outra cadeira eu montei o projeto de pesquisa e tal, montei a metodologia e fui apresentar pro professor da gente da cadeira, assim e ai ele virou pra minha cara e tipo: "Aah, por que tu vai falar sobre isso?" $\boldsymbol{E}$ eu ia falar sobre Afroempreendedores, né e ele: "Por que tu vai falar sobre isso, não tem importância?", tipo ele esculachou o meu trabalho e ai eu falei pra ele assim: "Tá, então tu anota ai que eu quero que a minha orientadora seja a Lélia Gonzalez"," porque dai eu fiquei pensando, né: "em algum momento ela vai ter que me acolher". Só que tipo, lá é por ordenamento então orientador também só vai te escolher se tu tiver um ordenamento bom e o meu ordenamento não era bom, né? Mais por sorte ela ainda tinha as cinco vagas e ele ainda virou pra minha cara e disse assim: "Ah, isso se tu der sorte, isso se tu tiver ordenamento pra pegar ela como orientadora". E aí tipo, eu fui direto nela, assim e falei "professora aconteceu isso, isso, isso, isso e isso" e ela falou na hora: "Não, isso é racismo!" E ai eu peguei e ela falou assim: "Não, vamos articular de uma forma que tu vai fazer teu trabalho" e foi ela que me recebeu assim, por que eu fiquei super agoniada, assim, mas durante o resto do curso não teve nenhum professor e até por essa questão de quando tu vai entrar no

\footnotetext{
${ }^{7}$ Nome fictício para a professora citada pela estudante. No caso, trata-se de uma professora negra tida como referência pela mesma.
}

Revista da ABPN • v. 11, Ed. Especial - Caderno Temático: Raça Negra e Educação 30 anos depois: e agora, do que mais precisamos falar? • abril de 2019, p.207-230 
movimento, quanto mais envolvido tu é pior fica pra ti perante os professores.

Virginia Leone Bicudo - Odontologia: É! Tem a de Medicina... Professores....

Nenhum deles são negros. São esses assim mais que apoiam cotas e vivem falando que são a favor e que o que a gente decidir eles nos apoiam. São esses...

André Rebouças - Engenharia Civil: Futuramente eu me sinto capaz sim de produzir conhecimento, quando eu tiver mais próximo assim do sétimo, sexto semestre, eu já. O meu grupo já desenvolve pesquisa assim, a gente é obrigado a desenvolver pesquisa, individual ou em grupo.

Essa relação de afinidade com os docentes é narrada com personagens que os apoiam em seus trabalhos, na compreensão dos temas do curso e na sua condição de costista. Além disso, essa relação também parece fortalecer a permanência, culminação e orientação a uma trajetória acadêmica. As poucas oportunidades de atuarem como pesquisadores(as) encaminham o diálogo para o tema da representatividade negra nos cursos:

Carolina Maria de Jesus - Medicina Veterinária: É, e sei lá, tipo, na questão da subrepresentação eu penso muito, agora já no final, né, eu penso muito na questão de: "Meus Deus o que é que eu vou fazer agora depois de me formar?". Eu fico pensando se eu quero continuar na faculdade fazendo mestrado, doutorado, sei lá... Virar professora pra servir como um exemplo lá pros próximos que vão entrar ou se eu vou pra parte da clínica e, sei lá, uma pessoa levar lá o seu cachorro e dizer assim: "Aãaahn, uma veterinária preta, que vai atender o meu cachorro!", sabe? Dai eu fico nessa paranoia assim de o que é que eu vou fazer agora?

Virginia Leone Bicudo - Odontologia: Mais, dentro da Odonto, eu penso muito em fazer pesquisa só que não tem um espaço, sabe? Tipo das coisas que eu idealizo sabe? Que eu penso, mas só dessa área mesmo que eu falei pra você que é mais do SUS, que é mais coisa assim, sabe, porque o restante não me chama nenhum pouco atenção. É o que eu falo: "Ah, eu nunca viraria professora porque eu não quero ser como eles”.

Teodoro Sampaio - Engenharia Mecânica: É, não é, mas o que eu vejo do pessoal negro no meu, assim, é que os que conseguiram e estão conseguindo chegar lá, eles são aqueles negros do... "O único negro do Rolê", aquele que ignora que tá sofrendo preconceito assim, e rir junto do branco qu tá do lado que tá fazendo preconceito com ele mesmo. Eles parecem que esquecem que são negros.

André Rebouças - Engenharia Civil: Uma das minhas intenções, assim, é conseguir conscientizar toda a minha família, meus sobrinhos, depois que eu me formar, conscientizar que a faculdade é bom, que eles tem o direito de tá lá, que eles devem estar lá, se quiserem, claro! E também de prestar serviço de engenharia, sabe, pra

Revista da ABPN • v. 11, Ed. Especial - Caderno Temático: Raça Negra e Educação 30 anos depois: e agora, do que mais precisamos falar? • abril de 2019, p.207-230 
pessoas que não tem condições de ter esse acesso e que precisam fazer uma obra de saneamento em casa, fazer um telhado novo... essas coisas. "Aaah, quero quebrar a parede da cozinha, mas não sei se a casa vai aguentar", sabe? E fazer mais que isso e serviços assim e através disso eu acredito, né, que através dessas ações é que aquela população em si vai se conscientizar que é possível de todos estarem lá, prestando esse auxílio, de ter um conhecimento e a partir desse conhecimento ir difundindo pros próximos, né... aquele espaço.

Nas trajetórias ilustradas, notamos que as situações de racismo vivenciadas pelos estudantes formam um contexto tenso e/ou inibidor na vida acadêmica. Isso ecoa na participação na pesquisa e nas perspectivas futuras de aprimoramento profissional. Nesse sentido, diante dessa sub-representação negra nas áreas de conhecimento em foco, buscamos identificar as boas práticas que vêm sendo desenvolvidas na UFGRS, como uma alternativa para esse cotidiano tão hostil que enfrentam os universitários negros cotistas.

Para isso, nosso objetivo com o grupo focal foi caracterizar essas demandas e experiências dos estudantes cotistas, assim como identificar quais perspectivas acerca das boas práticas e da permanência na universidade constroem os(as) estudantes negros(as) dos cursos pré-vestibulares em foco na áreas de Ciências Exatas, Biológicas, da Saúde e Tecnológicas na UFRGS, com ênfase nas estratégias e desafios do ingresso, permanência e sucesso na vida universitária. A identificação dessas perspectivas deve ser analisada em correlação tanto com as experiências dos cursos pré-vestibulares interlocutores nesta pesquisa, quanto com políticas implementadas pela UFRGS orientadas às ações afirmativas. É na triangulação entre essas perspectivas de boas práticas que poderemos identificar com maior claridade quais as boas práticas que estão promovendo efetivamente a permanência e fomentando a participação dos(as) estudantes cotistas nas ciências.

\section{CONSIDERAÇÕES FINAIS}

Ao longo deste artigo, buscamos contextualizar um cenário de ações afirmativas e caracterizar aspectos que afetam o ingresso e a permanência de jovens negros e negras em cursos das áreas de Ciências Exatas, Biológicas, da Saúde e Tecnológicas, com o fim de apresentar resultados que evidenciam obstáculos vividos pelos estudantes em seu ingresso, permanência e sucesso na vida universitária, como o enfrentamento ao racismo no meio acadêmico, e ao mesmo tempo estratégias que criam para lidar com esses desafios. 
Desse modo, para finalizar este artigo, ao cruzarmos os dados disponíveis com as “Trajetórias Negras e Ações Afirmativas" dos estudantes que compuseram as etapas 01 e 02 do grupo focal, destacamos quatro aspectos pertinentes de levar em conta para pensar políticas que favoreçam a permanência estudantil em cenários de políticas interculturais: o gênero, os imaginários raciais associados ao perfil da área, participação em pesquisa e prévestibulares populares.

- A participação feminina no grupo focal superou a masculina, no entanto isso não reflete a ocupação das mulheres negras nos cursos de exatas, ciências, tecnológicas e biológicas em termos quantitativos. Aquelas que se sobressaem evidenciam que ainda prevalece uma lógica acadêmica em que elas são a "exceção" e não a "regra" em áreas tidas como hegemonicamente masculinas, como nos cursos que abordamos: Ciências Contábeis, Engenharia Civil, Engenharia Metalúrgica, Odontologia e Medicina Veterinária. Nessa leitura da realidade que cerca as áreas, cabe trazer à tona a presença de um "homem trans e negro", conforme nosso interlocutor se autorreconhece, no curso de Engenharia Metalúrgica. No diálogo travado no grupo focal, observou-se que a interface entre a identidade de gênero e a racial revela-se conflitante no ambiente acadêmico. Esse jovem nos relatou que já pensou em mudar para a área de Humanas, tendo em conta uma possibilidade maior de aceitação social. Em estudos mais amplos é possível aprofundar essa problemática aqui suscitada.

O acesso às áreas de Exatas, Biológicas, Tecnológicas e Saúde é um tema que tanto nos cursinhos quanto para os estudantes é contraditório. Se, por um lado, são tidas como áreas de prestígio e, portanto, de maior chance de sucesso profissional, por outro são as que oferecem dificuldades em um grau elevado para sua permanência na universidade. Isso vai desde as disciplinas de cálculo, as quais possuem consideráveis índices de reprovação - e, nesse caso isso vem atrelado a uma formação deficiente em matemática no ensino fundamental e médio da escola pública - até à discriminação no cotidiano da interação universitária. No grupo focal nos foi relatado que no curso de Biologia, por exemplo, existe apoio psicológico para quem faz disciplinas iniciais, especialmente as obrigatórias, mas em outros cursos nem sempre há mecanismos de superação dessa barreira inicial. Além disso, os estudantes nos dizem que todo negro(a) cotista ou não nessas áreas é um "bode expiatório" sobre o qual recai a responsabilidade pela evasão ou retenção em disciplinas afins. Embora haja estudos que contradigam a ideia de que a evasão é maior entre quem acessou à 
universidade por ações afirmativas, esse é um "preço a se pagar" por estar nessas áreas. Um agravante é que o tom de competitividade e de não pertencimento a um padrão racial e de classe é mais acirrado nesses cursos. Essa trama de fatores inibe o acesso, mas dificulta especialmente a permanência no curso, configurada como um ser, estar e sentir-se parte da instituição (SITO, 2016).

- Há diferentes aspectos que afetam a participação na pesquisa, tanto as poucas oportunidades de participar de grupos de pesquisa ou extensão pela própria configuração das Faculdades (poucos grupos de pesquisa, processos excludentes de seleção, etc.), quanto a falta de estímulo ao protagonismo discente que inicia sua trajetória acadêmica. Se, como os alunos alegam, suas questões por vezes são ignoradas pelos docentes durante as aulas, ou ainda são objeto de desqualificação contínua na produção de conhecimento, como esperar deles participação nos grupos de pesquisa, laboratórios e outros grupos com esse foco? Por conta disso, trabalhamos com a hipótese de que as boas práticas precisam atingir também os docentes como rede de apoio aos estudantes e, de forma mais ampla, defesa e garantia das ações afirmativas. Um obstáculo a isso, sem dúvida, é o racismo, que, ao ser visto de forma estrutural e não de atitudes isoladas, nos possibilita identificar e caracterizar como isso afeta a permanência com sucesso na universidade. $\mathrm{O}(\mathrm{A})$ professor(a) é o sujeito de interface na produção de conhecimento e, se este refutar os sujeitos, também refuta tudo o que vem dele. Por essa via, nos interessou, como um desdobramento do projeto, trabalhar com docentes indicados pelos estudantes como referências não só teóricos ou profissionais, mas também políticos nas suas áreas (FREIRE, 2012[1970]). Talvez possamos provocar uma extensão das boas práticas que também atinja os docentes.

O papel dos cursinhos emerge como espaços que fortalecem não só o conhecimento formal para acesso às áreas de Exatas, Biológicas, Tecnológicas e Saúde, mas também espaços formativos críticos e de estabelecimento de laços comunitários antes e durante a graduação, os quais são uma aposta na amplitude da autoestima e protagonismo dos estudantes. Isso é importante se pensarmos na replicação dessas "boas práticas" nos coletivos negros que se formam na universidade como espaços de fortalecimento de laços, os quais têm nas ações afirmativas um ponto em comum. Também consideramos, a partir da análise, que esses espaços se potencializam quando estão articulados aos institucionais, pensados a partir da Coordenadoria de Ações Afirmativas e do Departamento de Educação 
e Desenvolvimento Social (da Vice-Reitoria de Extensão), por exemplo.

Esperemos que esses aspectos possam visibilizar desafios que dificultam mais a trajetória acadêmica de alguns jovens, assim como gerar políticas que favoreçam o ingresso, a permanência e o sucesso na vida universitária, potencializando as estratégias criadas pelos própios estudantes.

\section{REFERÊNCIAS}

BARBOUR, Rosaline. Grupos focais. Porto Alegre: Artmed, 2009.

FREIRE, P. Pedagogía del oprimido. Madrid: Biblioteca Nueva, 2012. [1970].

MACHADO, Carlos. Negros e negras inventores, cientistas e pioneiros. Londrina: Eduel, 2013. MASON, J. Qualitative researching. London: SAGE Publications, 1996.

MINAYO, M. C. S.; SANCHES, O. Quantitativo-qualitativo: oposição ou complementaridade? Cadernos de Saúde Pública, v. 9, n. 3, p. 239-262, 1993.

SCHUMAHER, Schuma; VITAL BRAZIL, Érico. Mulheres negras do Brasil. Rio de Janeiro: Senac, 2007.

SITO, L. Escritas Afirmativas: estratégias criativas para subverter a colonialidade em trajetórias de letramento acadêmico. 297 p. Tese (Doutorado em Linguística Aplicada) - Universidade Estadual de Campinas, Campinas, 2016.

SITO, L.; FERREIRA, J.; RODRIGUES, T. O processo de implementação das Ações Afirmativas na UFRGS. In: TETTAMANZY, A. L. et al. Por uma política de ações afirmativas: problematizações do Programa Conexões de Saberes/UFRGS. Porto Alegre: PROTEXT/UFRGS, Editora da UFRGS, 2008.

UNIVERSIDADE FEDERAL DO RIO GRANDE DO SUL - UFRGS. Programa de Ações Afirmativas da UFRGS. 2008-2012. Porto Alegre: Editora UFRGS. Relatório bianual do Programa de Ações Afirmativas. Permanência e desempenho discente 2013-2015.

UNIVERSIDADE FEDERAL DO RIO GRANDE DO SUL - UFRGS. Decisão 134 de 2007, de 29 de junho de 2007.

Recebido em janeiro de 2019 Aprovado em março de 2019 